\section{Effects of atropine on heart rate and hippocampal EEG following septal stimulation in rats'}

\section{B. M. CHALMERS and T. L. HOLDSTOCK, Witwatersrand University, Johannesburg, South Africa}

Small doses of methyl atropine attenuated heart rate deceleration following stimulation of the lateral septal area more than equally small doses of atropine sulphate. Neither drug seemed to affect hippocampal activity before or after stimulation. At times the electrical stimulation elicited seizure discharges in the hippocampus.

Several studies in our own (Bromley \& Holdstock, in press; Holdstock, 1967) and in other laboratories (Covian et al, 1964; Covian et al, 1966; Manning et al, 1963) have attempted to elucidate the mechanism by which stimulation of the septal area produces heart rate (HR) deceleration. Some of this work indicated that the slowing was due to activation of the parasympathetic nervous system (Bromley \& Holdother studies implicated inhibition of sympathetic tone (Covian et al, 1964; Holdstock, 1967; Manning et al, 1963). The most likely explanation for these conflicting results can be made in terms of species Using vagotomy and cholinergic blocking agents, studies with cats have indicated that HR deceleration was mediated by inhibition of sympathetic tone (Covian et al, 1964; Manning et al, 1963). On the other hand, data obtained from vagotomized rats suggested that vagal activation was responsible for the slowing of HR (Bromley \& Holdstock, in press; Covian et al, 1966). However, no systematic investigation has been carried out on the effects of cholinergic blocking drugs in rats. Thus, in the present study an attempt was made to investigate the effects of septal stimulation on HR following the administration of two derivatives of atropine: atropine sulphate and methyl atropine nitrate $(\mathrm{MeA})$. Whereas atropine sulphate blocks cholinergic functions in the central as well as in the peripheral nervous system, MeA passes from the bloodstream into the brain rather poorly. The possibility exists, however, that it will effect changes in heart rate more than atropine sulphate, for MeA has been shown peripheral anticholinergic effects (see Carlton, 1963, for references). stock, in press; Covian et al, 1966), while differences (Bromley \& Holdstock, in press). to be more potent with respect to certain
Recordings of hippocampal EEG activity were also obtained to study the relationship of the decelerative cardiac response to changes in hippocampal activity. Some relation was expected in view of the striking parallelism Torii \& Kawamura (1960) reported between hippocampal activity and blood pressure changes following amygdaloid stimulation. Covian et al (1966) actually suggested that blood pressure hypotension following septal stimulation could be mediated through the hippocampus. On the basis of the close anatomical connections between the septal area and hippocampus it can be argued that hippocampal electrical activity may also serve as an indicator of cardiac functioning following stimulation of the septal area.

SURGERY AND HISTOLOGY

A stereotaxic instrument was used to implant bipolar electrodes in the septal area of 18 hooded rats $(250-300 \mathrm{~g})$. In half of the animals another bipolar electrode was implanted in the dorsal hippocampus and in the other half in the ventral hippocampus. The coordinates used for the implants are given in Table 1. The electrodes were made of .007-in. Teflon-coated stainless-steel wire attached to an Amphenol strip connector. The wires were insulated to approximately $0.50 \mathrm{~mm}$ from the tips which were about $0.75 \mathrm{~mm}$ apart. HR was recorded from two 26-gauge stainless-steel wires. Each wire was looped through the skin, and the ends were then twisted together. All operations were carried out under pentothal anesthesia. When necessary, atropine $(5.0 \mathrm{mg} / \mathrm{kg})$ was administered during surgery to ease respiration.

At completion of the experiment the animals were perfused with isotonic saline followed by $10 \%$ formalin. The brains were then removed and fixed in $10 \%$ formalin. Frozen-tissue technique was used to prepare sections that were $50 \mu$ thick.

\section{APPARATUS}

Stimulation was delivered by a Grass Model SDS stimulator in series with a Grason-Stadler E1 $100 \mathrm{H}$ timer. The stimula- tion consisted of a 0.5 -sec train of biphasic pulses (pulse duration, $0.2 \mathrm{msec}$; frequency, $100 \mathrm{cps}$ ). HR and EEG were recorded on a Beckman Type R dynograph.

\section{PROCEDURE}

Six days after surgery the animals were restrained on a platform with straps. They were adapted to this position for a 1-h period in a sound-insulated chamber that was electrically shielded. On the following day the first of three experimental sessions began. On each occasion the Ss received an injection of normal saline, atropine sulphate, or MeA. All injections were done intraperitoneally. An atropine dosage of $0.01 \mathrm{mg} / \mathrm{kg}$ was used at a constant volume of $2 \mathrm{cc} / \mathrm{kg}$. The order in which the drugs were presented followed a standard 3 by 3 Latin-square design.

lmmediately following an injection the animals were restrained. Fifteen minutes elapsed before the first of 10 electrical stimulations was presented. The initial voltage was set at $3.0 \mathrm{~V}$, and the intensity increased in steps of $1.0 \mathrm{~V}$ to a maximum of $7.0 \mathrm{~V}$. The series of stimulations was then repeated once more. The interval between stimulations was varied randomly around a mean of $2 \mathrm{~min}$. Seven days were allowed to elapse between experimental sessions.

Measurements of HR and EEG were obtained for at least $5 \mathrm{sec}$ before each presentation of the stimulus until at least $10 \mathrm{sec}$ after stimulation. The HR response to stimulation was expressed in relation to baseline scores. Measurements of HR were obtained for 1 -sec periods from the first second before stimulation to the fourth second after stimulation. Changes in interbeat interval (IBI) were derived by subtracting prestimulation from poststimulation values.

\section{RESULTS \\ Heart Rate}

Histological analysis revealed that the stimulating electrodes were all anterior in the lateral septal area. Ten of the placements were very dorsal, while five were medioventral, and two were somewhat more ventral in the lateral septal area. The brain of one animal was lost.

Figure 1 shows that although stimulation of the septal area produced HR decele ration under all conditions, the effect was less pronounced following administration of atropine. The difference between the experimental treatments was verified statis-
Table 1

Target Coordinates (mm) for Electrode Placements

\begin{tabular}{llccc}
\hline Placement & $\begin{array}{l}\text { Anterior (+) } \\
\text { posterior (-) } \\
\text { to bregma }\end{array}$ & $\begin{array}{c}\text { Lateral from } \\
\text { midline }\end{array}$ & $\begin{array}{c}\text { Depth below } \\
\text { cortex }\end{array}$ & $\begin{array}{c}\text { Angle to } \\
\text { midline }\end{array}$ \\
\hline Septal & +0.75 & 2.50 & 5.00 & $17 \mathrm{deg}$ \\
Dorsal Hippocampus & -3.00 & 2.50 & 2.75 & $0 \mathrm{deg}$ \\
Ventral Hippocampus & -4.25 & 6.00 & 4.50 & $9 \mathrm{deg}$ \\
\hline
\end{tabular}




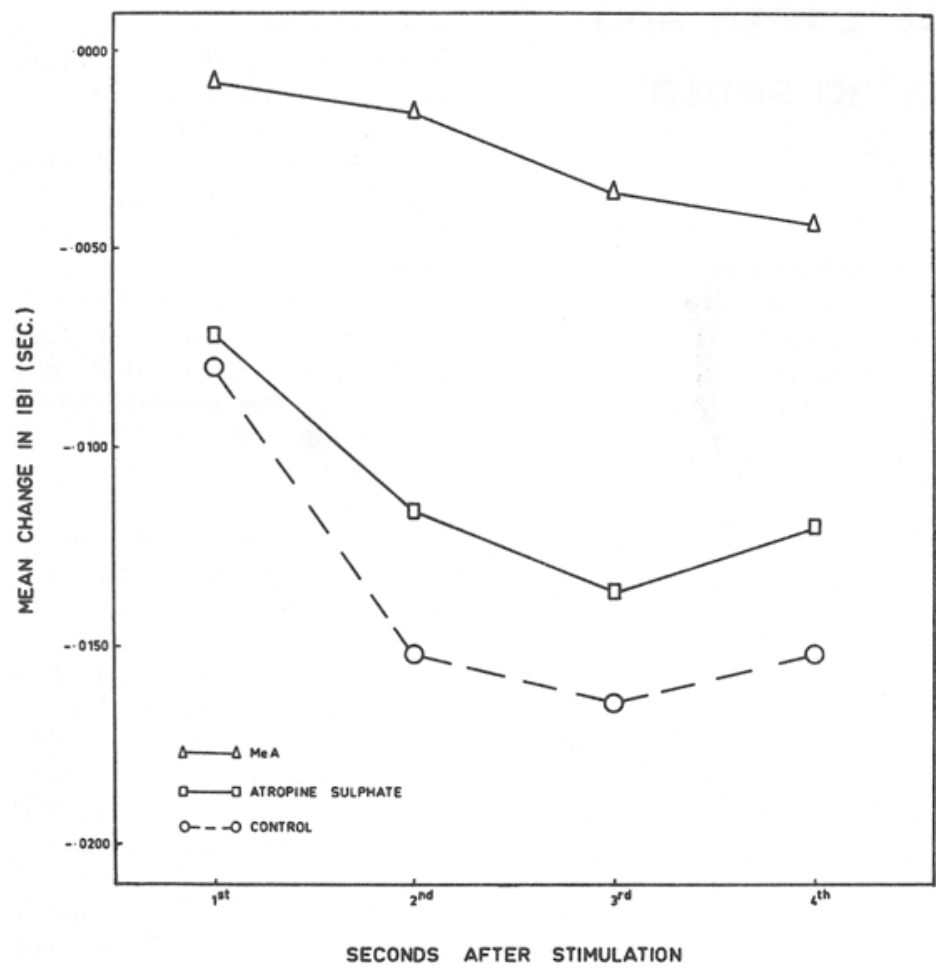

tically in an analysis of the data for the third second after stimulation $(F=10.49$, $\mathrm{df}=8 / 45, \mathrm{p}<.001$ ). Duncan's New Multiple Range Test, furthermore, differentiated the $\mathrm{MeA}$ from the control and atropine sulphate conditions at the .005 level. There was, however, no significant difference between the latter two conditions.

The difference between the treatment conditions is also reflected in the latency of the decelerative effect. Whereas some animals exhibited a mean HR acceleration during the first 2 sec after stimulation under MeA conditions, no acceleration was obtained duling this period under the other conditions.

\section{EEG}

Figure 2 illustrates examples of various patterns of EEG activity recorded from the dorsal hippocampus. The most prominent change elicited by septal stimulation consisted of seizure discharges (Panel B), which were similar in character to that described by Porter et al (1959) as a response to hippocampal stimulation. Eight of the Ss with recording electrodes in the dorsal hippocampus, and four with ventral hippocampus placements, displayed paroxysmal afterdischarges at one stage or another
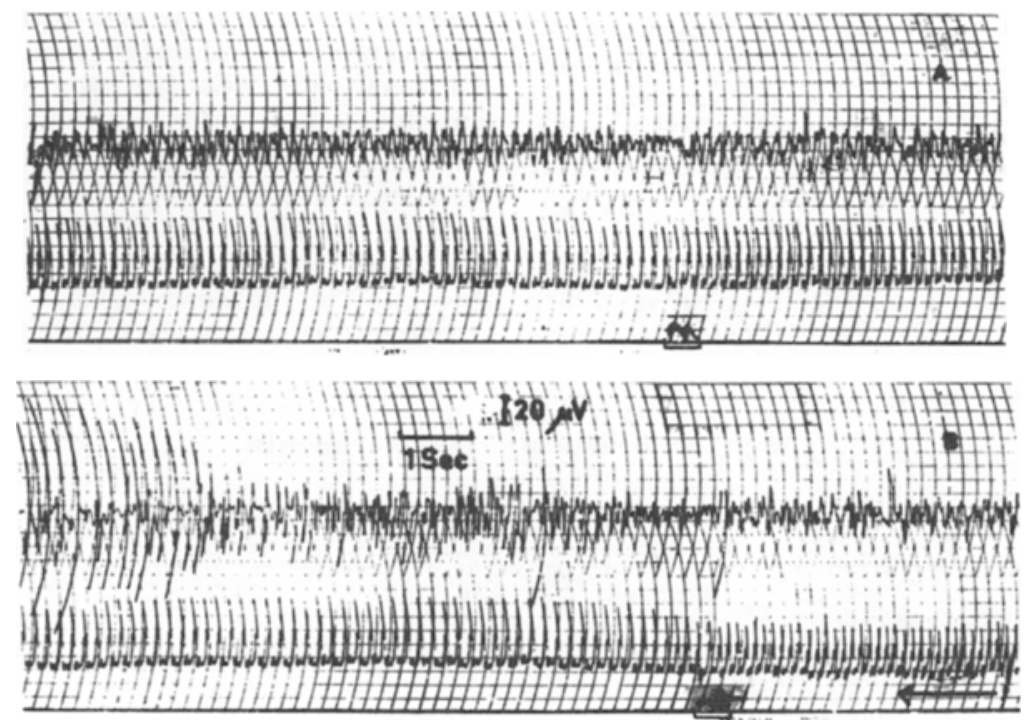

Fig. 1. Mean change in IBI for the first 4 sec following septal stimulation.

during the experiment. However, the difference between the placements can probably be explained by the fact that, in contrast to the dorsal electrodes, only two of the ventral placements were clearly in the hippocampus. Administration of atropine did not influence the frequency with which seizure discharges occurred, nor did it affect the activity recorded during baseline conditions. The dominant rhythm before stimulation consisted of 6-7 cps. DISCUSSION

The findings of this study suggest that HR deceleration following septal stimulation is due to the effects of vagal activation. Although the atropine dosages were very small, both derivatives of the drug attenuated the effects of stimulation. The greater potency of MeA could be due to the fact that it has been shown to block peripheral cholinergic activity more effectively than atropine sulphate (see Carlton, 1963, for references). Inspection of the baseline HR values eliminated the possibility that the difference between the experimental conditions could be accounted for by the law of initial values.

The conclusion that the deceleration is due to activation of the parasympathetic nervous system agrees with the findings obtained by vagotomy in rats (Bromley \& Holdstock, in press; Covian et al, 1966). It is also consistent with the results obtained following administration of atropine to three rats in the study by Covian et al (1966). Although most of the work with cats suggested that inhibition of sympathetic activity was involved (Covian et al, 1963; Manning et al, 1963), some findings with this species nevertheless support the conclusion drawn in the present study. Covian \& Timo-Iaria (1966), for instance, found that eserine, an anticholinesterase, enhanced cardiac slowing following septal stimulation.

Despite the noticeable effects of atropine on the cardiac response to septal stimulation, the drug did not appear to have as clear-cut an effect on hippocampal activity. The reason for this may be twofold. In the first instance MeA, which had the greatest effect on HR, reportedly does not cross the blood brain barrier (Carlton, 1963). Secondly, although it is well known that atropine synchronizes EEG, this only occurred when

Fig. 2. Representative patterns of HR and hippocampal EEG before and after stimulation. The upper tracing in each panel represents hippocampal activity while the middle tracing in each panel represents HR. Presentation of electrical stimulation is indicated on the bottom line of each panel. 
doses very much larger than those used in this study were administered (Longo, 1966). Thus it seems possible to differentiate the cardiac from the hippocampal effects of septal stimulation. Figure $2 \mathrm{~A}$ clearly indicates that HR slowing was evident before any EEG changes occurred, and that the deceleration may even take place without any concomitant changes in hippocampal activity.

\section{REFERENCES}

BROMLEY, D. V., \& HOLDSTOCK, T.L. Effects of septal stimulation on heart rate in vagotomized rats. Physiology \& Behavior, in press.

CARLTON, P. L. Cholinergic mechanisms in the control of behavior by the brain. Psychological Review, 1963, 70, 19-39.

COVIAN, M. R., ANTUNES-RODRIQUES, J., \& O'FLAHERTY, J. Effects of stimulation of the septal area upon blood pressure and respiration in the cat. Joumal of Neurophysiology, 1964, 27, 394-407.

COVIAN, M. R., LICO, M. C., \& ANTUNESRODRIQUES, J. Blood pressure and respiratory changes by stimulation of the brain septal area in rats. Acta Physiologica Latino Americana, 1966, 16, 99-105.
COVIAN, M. R., \& TIMO-IARIA, C. Decreased blood pressure due to brain septal stimulation. bradycardia, baroreceptor reflex. Phy siology \& Behavior, 1966, 1, 37-43.

HOLDSTOCK, T. L. Effects of septal stimulation in rats on heart rate and galvanic skin response. Psychonomic Science, 1967, 9, 37-38.

LONGO, V. G. Behavioral and electroencephalographic effects of atropine and related compounds. Pharmacological Review, 1966, 18, 965-996.

MANNING, J. W., CHARBON, G. A., \& COTTEN, M. de V. Inhibition of tonic cardiac sympathetic activity by stimulation of the brain septal region. American Joumal of Physiology, 1963, 205, 1221-1226.

PORTER, R. W., CONRAD, D. G., \& BRADY, J. $V$. Some neural and behavioral correlates of electrical self-stimulation of the limbic system. Journal of the Experimental Analysis of Behavior, 1959, 2, 43-55.

TORII, S., \& KAWAMURA, H. Effects of amygdaloid stimulation on blood pressure and electrical activity of hippocampus. Japanese Joumal of Phy siology, 1960, 10, 374-384.

\section{NOTE}

1. This study was supported by the South African Council for Social Research. Based on a postgraduate honors thesis by B. M. Chalmers.

\section{The effect of prior rewarded goal box placements on incentive reduction behavior'}

STEPHEN F. DAVIS, Texas Christian University, Fort Worth, Tex. 76129, and ALVIN J. NORTH, University of Texas Southwestern Medical School, Dallas, Tex. 75235

Two groups of rats received 92 preacquisition rewarded goalbox placements or 92 preacquisition handling trials. These were followed by 24 large-reward trials for both groups. In a third phase (incentive reduction) all Ss received 16 small-reward trials. The results indicated greater disruption of performance during the incentivereduction phase for the group receiving the preacquisition placements. The greatest disruption of performance was noted in the start measure. Possible interpretations are offered.

A recent study by Davis \& North (1968) was concerned with the effect of number of large-reward trials given before an incentivereduction phase. The results indicated that
Ss given a large number of such trials showed a greater disruption in performance, especially in start speeds, during incentive reduction than a group receiving a small number of large-reward trials before the reduction of incentive. One possible explanation for these results stems from frustration theory (Amsel, 1958; Spence, 1960), and more specifically the assumption that strength of conditioning of $r_{g}-s_{g}$ during acquisition increases with increase in the number of rewards at the goal. Consequently, one would expect greater elicitation of frustration during incentive reduction for the group receiving the large number of preshift trials. Similarly, it would be expected that $r_{g}-s_{g}$ would be more strongly conditioned for a group of $\mathrm{Ss}$ receiving a series of preacquisition rewarded goal-box placements as compared with a group receiving a series of nonrewarded handling trials before acquisition. If the number of acquisition trials preceding incentive reduction is equated for both groups, then incentive-reduction behavior should be more disrupted for the group receiving the preacquisition goal-box placements. The present experiment was designed to test this prediction. SUBJECTS

Twenty-four male, albino rats purchased from the Holtzman Company, Madison, Wis., served as Ss. The Ss were approximately 90 days old at the beginning of the experiment. All Ss were housed in individual cages with water continuously available. During the experiment the Ss were maintained on a daily deprivation schedule consisting of $12-14 \mathrm{~g}$ of Purina Lab Chow per S. All Ss were fed 15-30 min after the completion of the daily experimental session.

\section{APPARATUS}

The apparatus (more fully described in Davis \& North, 1967) was a single 4-ft 10-in. straight runway having a white start box and black run section and goal box. Photocells located 8 in., 14 in., 32 in., and 40 in. beyond the start door yielded start, two run, and goal times on standard electric timers. The total time from the raising of the start door to the breaking of the last photobeam in the goal box was shown on a fifth timer. PROCEDURE

Following 1 week of experience with the deprivation schedule, all $S s$ received an 8-day pretraining phase. Pretraining consisted of handling and taming, habituation to the reward pellets in a neutral box, and habituation to the unbaited apparatus in groups of three and singly. At the end of the pretraining phase the Ss were randomly assigned to two equal groups ( $\mathrm{P}$ and $\mathrm{H}$ ). Ss in Group $P$ received 92 direct, large-reward (15 45-mg Noyes pellets) goal-box placements, followed by 24 large-reward runs. Ss in Group $\mathrm{H}$ received 92 nonreward handling trials, followed by 24 large-reward runs. A handling trial consisted of placing $S$ into a cardboard box $(12 \times 12 \times 12$ in. $)$ for $15 \mathrm{sec}$ and then returning him to his home cage. Following the 24 large-reward runs both groups received 16 small-reward (1 $45-\mathrm{mg}$ Noyes pellet) runs. Trials were administered at the rate of four trials per day during the handling/placement phase, and at the rate of one trial per day during the last two phases. The daily order for running $S$ s was completely randomized. On all trials Ss were removed from the apparatus as soon as the last piece of food was taken into the mouth. RESULTS

Figure 1 shows mean start, run (24-in. section), and goal speeds over blocks of two trials at terminal acquisition (TA) and during the incentive-reduction phase. A trend analy sis of variance was performed for each of these measures with the following results being obtained. The trials factor was significant for the goal measure $(F=4.48$, 